\title{
Preliminary Remarks in Hormonal Treatments Effects on Reproduction Period in Cows
}

\author{
Ioana Cristina CRIVEI ${ }^{1)}$, Elena RUGINOSU ${ }^{2)}$, S.I. BORŞ ${ }^{2)}$, D. L. DASCĂLU ${ }^{2)}$, \\ P. ROŞCA ${ }^{1)}$, D. DRUGOCIU ${ }^{1)}$. \\ 1) Department of Clinics, Faculty of Veterinary Medicine, M.Sadoveanu Street, No. 8, Iași, Romania. \\ 2) Research and Development Station for Cattle Breeding Dancu - IASI SCDCB Holboca village, No 9 Sos. \\ Iasi-Ungheni, Romania. \\ *Corresponding author: i.crivei@uaiasi.ro
}

Bulletin UASVM Veterinary Medicine 73(1) / 2016,

Print ISSN 1843-5270; Electronic ISSN 1843-5378

DOI:10.15835/buasvmcn-vm: 11701

\begin{abstract}
The early resumption of estrous cycles following calving is important for high reproductive efficiency, but also for the cows which haven't been observed in estrus during the first 60 days after calving, the last ones having a significantly higher risk of being culled than cows that have displayed estrus (Opsomer et al., 2000).

The aim of this study was to determine the effect of hormonal treatment on reproduction period in cows, and also to establish if there is any significant difference in some reproductive parameters between cows treated with hormonal medication and cows which resumed ovarian cyclicity before 60 days postpartum.

This study was performed in a dairy cow's farm in North-Eastern Moldavia, over a period of 2 consecutive years, on Romanian Black Spotted cows, in order to determine hormonal treatments influence over reproduction period. Hormonal treatments used for the above mentioned diseases were represented by luteolytic agent prostaglandin F2 $\alpha$, one of its potent analogues (Proliz, Biotur, Romania) and by administration of exogenous gonadotrophin releasing hormone (Receptal, Intervet, Romania).

We noticed that average reproduction period (52.1 days) and the other breeding intervals that were taken under study (over a two years period), presented different values for cows that have been under hormonal medication treatment, compared to those which resumed ovarian cyclicity before 60 days postpartum (52.7 days).

Thus, this preliminary study supports the development of a more detailed study on several dairy cows' farms in order to investigate the answer of different types of hormonal treatments against persistent corpus luteum and cystic ovarian disease.
\end{abstract}

Keywords: cows, hormonal treatment, ovarian diseases, reproduction period

\section{INTRODUCTION}

Delays in oestrus expression and commencement of ovulation are associated with reduced conception and pregnancy rates and also by increased intervals from calving to conception (Rhodes et al., 2003).

The early resumption of oestrous cycles following calving is important for high reproductive efficiency and for that, cows that have not been observed in oestrus during the first 60 days after calving have a significantly higher risk of being culled than cows that have displayed estrus (Opsomer et al., 2000).

Recent researches suggested that approximately $20 \%$ of dairy cows have neither displayed oestrus nor ovulated before the start of the breeding period (Opsomer et al., 2000; Moreira et al., 2001).

There are many factors that influence time to first ovulation, and whether normal oestrus and ovulatory cycles are maintained thereafter, including breed, season, body condition score, 
peripartum disease, and a variety of nutritional effects (Butler, 2000).

The occurrence of prolonged period of ovarian quiescence is mainly due to lowered plasma luteinizing hormone (LH) level.

Factors that suppress LH pulse frequency are including energy deficiency, stress factors, endogenous opioid peptide, suckling and lowered insulin concentration (Grunert et al., 1981).

The aim of the present study was to determine the effect of hormonal treatments on reproduction period in cows, to establish if there is any significant difference in some reproductive parameters between cows treated with hormonal medication and cows which resumed ovarian cyclicity before 60 days postpartum.

Reproduction period is defined as the period between first insemination and fecund insemination (Hanzen, 2015).

Finally, we also aimed to analyze the response to hormonal treatments according to the season and if the treatment response is seasonally influenced.

\section{MATERIALS AND METHODS}

The study was conducted in a dairy farm located in North Eastern of Romania, on 160 Romanian Black Spotted Breed dairy cows, over a period of two consecutive years.

The cows were housed in a free stall housing system during summer time and in a tied stall housing system during the cold season. Body condition of the animals was good and the average annual milk production was between 6200-6300 litres/normal lactation/cow.

All the data about animals taken under study was recorded from the official register of the dairy farm, over a period of 2 consecutive years and were derived from 80 treatments given to anestrous cows which presented persistent corpus luteum and ovarian cysts. The first group was represented by 80 cows, with no estrous activity before 60 days postpartum (cows with ovarian cysts and persistent corpus luteum), and the second group was represented by 80 cows that resumed ovarian cyclicity before 60 days postpartum.

Transrectal examination of the ovaries was performed both in cows from the experimental groups, for detection of persistent corpus luteum and ovarian cysts, before the administration of hormonal treatments, and also for cows from the control group, which resumed ovarian cyclicity during the first 60 days postpartum.

The main objective of performing transrectal examination was to diagnose the presence or the absence of a persistent corpus luteum and ovarian cysts, without insisting on ratio of follicular vs. luteal cysts and it was performed using a $7.5 \mathrm{MHz}$ linear transducer (WED 3000V, Hasvet Medical Consulting, Turkey).

All the cows with persistent corpus luteum were treated with Proliz (PGF2 $\alpha$ - Biotur, Romania), $2 \mathrm{ml} /$ cow and cows with ovarian cysts were treated with Receptal (Gn-RH - Intervet, Romania), $5 \mathrm{ml} /$ cow. The treatments were applied for 80 cows that during the first 60 days postpartum were not detected to be in estrus.

Based on obtained data from the official register of the dairy farm, the following indices breeding were analyzed: interval from treatment to first artificial insemination (T-1AI), interval from treatment to fecund artificial insemination (T-FAI), interval from calving to first artificial insemination (C-1AI), reproduction period (RP), and conception rate (CR), service period (SP) and calving interval $(\mathbf{C I})$.

\section{RESULTS AND DISCUSSION}

The analysis of the recorded data within this study indicates some differences for those two years included in the study. Cows with postpartum anoestrus which were treated using hormonal medicine, presented different values for the monitored parameters, compared with cows which resumed ovarian cyclicity before 60 days postpartum.

Thus, cows that were diagnosed with persistent corpus luteum were inseminated (AI) within an average interval of 22.1 days after treatment over the two years of study. Also, cows were diagnosed as being pregnant within an average interval of 74.2 days after treatment (Tab. 1).

The interval from calving to first artificial insemination in cows with persistent corpus luteum, for those 2 years of study, presented an average interval of 142.4 days, compared to cows from the control group (49.6 days) (Tab. 2).

For the two years included in the study, reproduction period in cows with persistent corpus luteum presented a lower average interval of 51.6 days (Tab. 1), compared to cows from the 
control group, which had an average interval of 60 days (Tab. 2).

Pregnancy index presented an average value of 2.3 for cows from the experimental group and an average of 2.9 for the control group (Tab. 1, 2).

Conception rates after treatment for these two years of study in cows with persistent corpus luteum, display a high percentage at the $1^{\text {st }}$ insemination (35\%), followed by an obvious decrease until the $4^{\text {th }}$ insemination $(12.5 \%)$.

For the control group, conception rates present moderate decreases until the $3^{\text {rd }}$ insemination $(11.3 \%)$, and starting with the $4^{\text {th }}$ insemination, conception rates are recording a value of $33.7 \%$ (Fig. 1).

Cows that were diagnosed and treated against ovarian cysts, were inseminated within an average interval of 24.2 days after treatment, and were diagnosed as being pregnant in an average interval of 77.7 days after treatment (Tab.3).

The interval from calving to first artificial insemination in cows with ovarian cysts reported an average interval of 139.8 days, compared to cows from the control group, which presented an average interval of 49.6 days (Tab. 4).

Reproduction period for cows with ovarian cysts presented a lower average interval (53.6

Tab.1. Breeding indices in cows with persistent corpus luteum (E1 group) after treatment according to the year

\begin{tabular}{ccccccccc}
\hline Year & C-1T & T-1AI & T-FAI & C-1AI & RP & AI/G & SP & CI \\
\hline $1^{\text {st }}$ & 123.05 & 21.2 & 83.20 & 144.3 & 61.95 & 2.45 & 206.25 & 488.45 \\
\hline $2^{\text {nd }}$ & 117.5 & 23 & 65.10 & 140.5 & 41.25 & 2.15 & 183.00 & 464.95 \\
\hline Average & 120.3 & 22.1 & 74.2 & 142.4 & 51.6 & 2.3 & 194.6 & 476.7 \\
\hline
\end{tabular}

Tab. 2. Breeding indices in cows from the control group according to the year

\begin{tabular}{cccccc}
\hline Year & RP & C-1AI & AI $/ G$ & SP & CI \\
\hline $1^{\text {st }}$ & 63.3 & 48.2 & 3.03 & 111.5 & 394 \\
\hline $2^{\text {nd }}$ & 56.7 & 51.1 & 2.8 & 107.8 & 390.5 \\
\hline Average & 60 & 49.6 & 2.9 & 109.6 & 392.2 \\
\hline \multicolumn{5}{c}{ " Control group } & - Cows with persistent corpus luteum
\end{tabular}

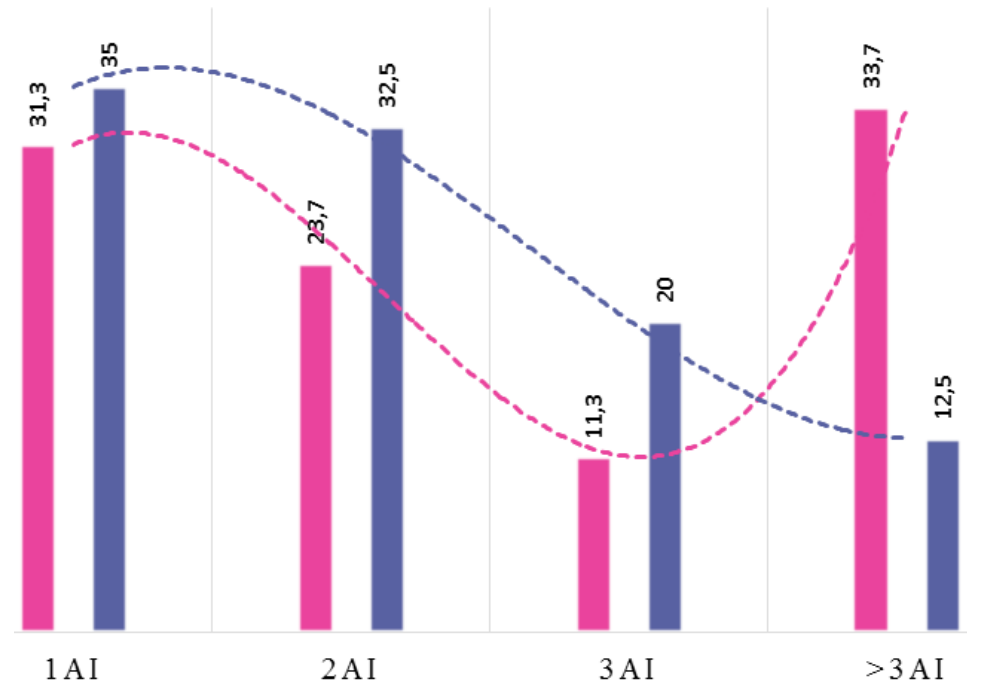

Fig. 1. Conception rates after treatment in cows with persistent corpus luteum 
days) (Tab. 3), compared to cows from the control group (60 days) (Tab. 4).

For those two years included in our study, the number of artificial inseminations performed to obtain a gestation, had an average of 2.5 artificial inseminations for the experimental group and an average of 2.9 artificial inseminations for the control group (Tab. 3, 4).

For the period taken under study, cows treated against ovarian cysts presented high values for conception rates during $1^{\text {st }}$ and $2^{\text {nd }}$ artificial inseminations (30\%), followed by an obvious decrease $(17.5 \%)$ for the $3^{\text {rd }}$ artificial insemination and starting with the $4^{\text {th }}$ artificial insemination, conception rates presented a slight increase $(22.5 \%)$.
For the control group, conception rates presented a decreasing tendency starting with $1^{\text {st }}$ artificial insemination (31.3\%), till $11.3 \%$ for the $3^{\text {rd }}$ artificial insemination, following to present an ascending trend starting with the $4^{\text {th }}$ artificial insemination.

By analyzing treatment response according to the season, we aimed to highlight how many cows were diagnosed as being pregnant for each season (both for treated cows and also for those in the control group) and if the treatment response is influenced by the season.

According to recorded data from the dairy farm official register, the treated cows against persistent corpus luteum showed best responses during winter season, when $37.5 \%$ of the cows

Tab. 3. Breeding indices in cows with ovarian cysts (E2 group) after treatment according to year

\begin{tabular}{ccccccccc}
\hline Year & C-1T & T-1AI & T-AIF & C-1AI & RP & AI/G & SP & CI \\
\hline $1^{\text {st }}$ & 118.00 & 23.00 & 76.70 & 141.00 & 53.70 & 2.30 & 194.70 & 477.20 \\
\hline $2^{\text {nd }}$ & 112.90 & 25.30 & 78.70 & 138.55 & 53.40 & 2.75 & 201.50 & 484.05 \\
\hline Average & 115.5 & 24.2 & 77.7 & 139.8 & 53.6 & 2.5 & 198.1 & 480.6 \\
\hline
\end{tabular}

Tab. 4. Breeding indices in cows from the control group according to the year

\begin{tabular}{cccccc}
\hline Year & RP & C-1AI & AI/G & SP & CI \\
\hline $1^{\text {st }}$ & 63.3 & 48.2 & 3.03 & 111.5 & 394 \\
\hline $2^{\text {nd }}$ & 56.7 & 51.1 & 2.8 & 107.8 & 390.5 \\
\hline Average & 60 & 49.6 & 2.9 & 109.6 & 392.2 \\
\hline
\end{tabular}

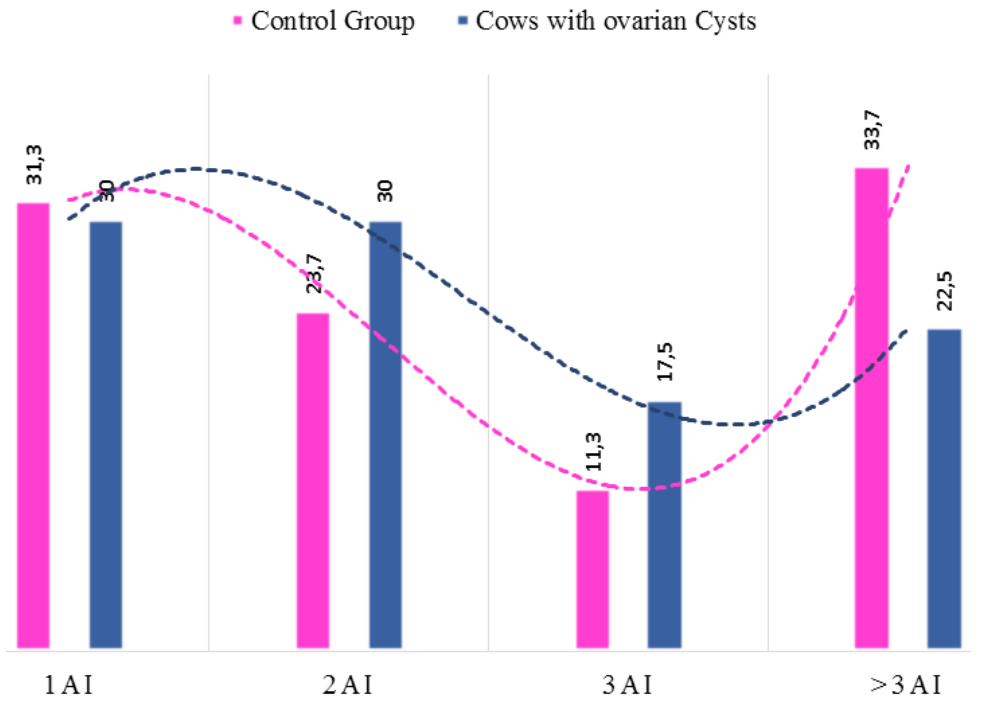

Fig. 2. Conception rates after treatment in cows with ovarian cysts 
included in this group were diagnosed as being pregnant.

This result is followed by a value of $22.5 \%$ pregnant cows, recorded during spring season and by similar values of $20 \%$ during summer and autumn seasons (Fig.3).

For the control group, the percentage of diagnosed cows as being pregnant during winter season $(35 \%)$ is quite near to the same season in the experimental group, the same situation being encountered also for warm period of the year (spring-summer), $20 \%$ of the cows being diagnosed as pregnant (Fig. 3).
From the total treated cows against ovarian cysts, for the period taken under study, the highest percentage of pregnant diagnosed cows was recorded during summer season (30\%), followed by autumn season with a percentage of 27.5 (Fig. 4).

Further on, during winter season, the percentage of cows that were diagnosed as being pregnant has decreased, so during spring season, only $20 \%$ of the total treated and inseminated cows were diagnosed as pregnant (Fig. 4).

For the control group, the percentage of pregnant diagnosed cows registered an upward

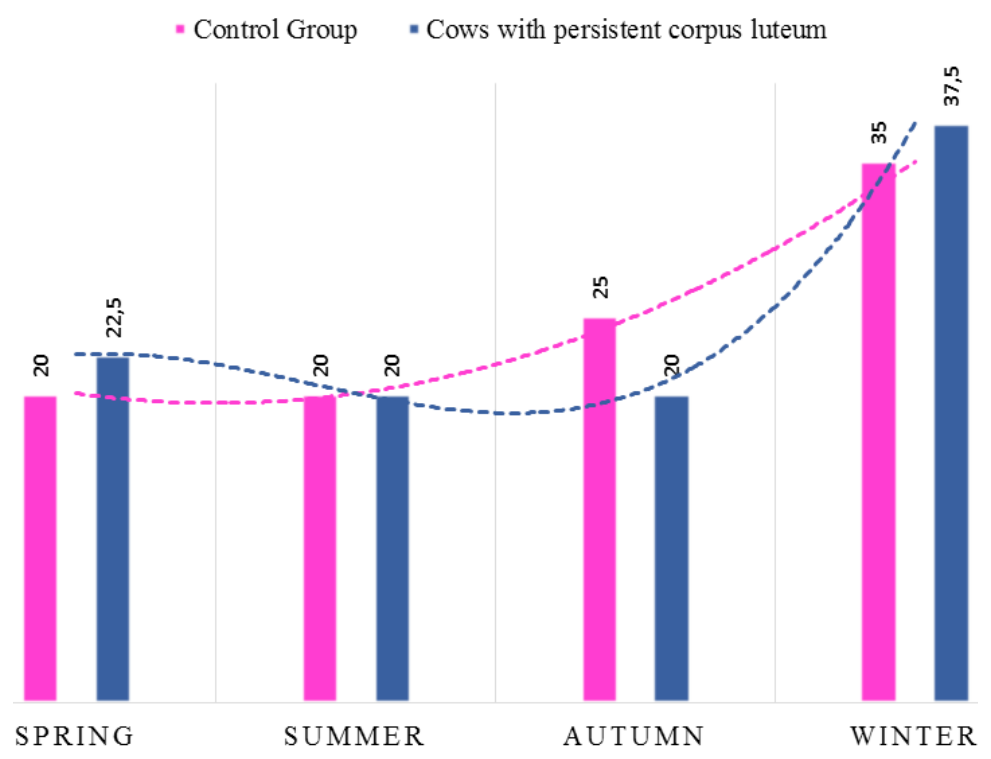

Fig. 3. Treatment response of cows with persistent corpus luteum according to the season

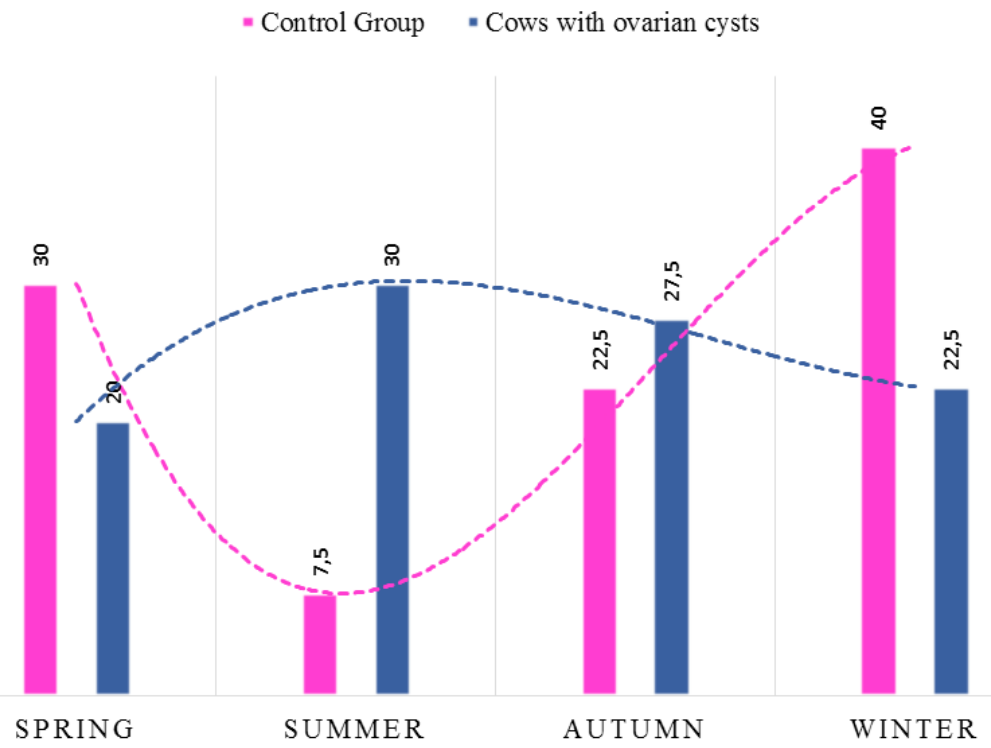

Fig. 4. Treatment response of cows with ovarian cysts according to the season 
trend during cold period of the year, so $40 \%$ of the total cows were diagnosed as being pregnant during winter and $30 \%$ in the spring season. On the opposite, during summer season, the percentage of pregnant diagnosed cows was 7.5 and 22.5 during autumn (Fig. 4).

This study is the first of its kind and we aimed to determine the effect of hormonal treatments on reproduction period in dairy cows, to establish if there are differences in some reproductive parameters between cows treated with hormonal medication and cows that resumed ovarian cyclicity before 60 days postpartum.

According to Hanzen (2015), the reproduction period is defined as being the period between first and fecund insemination or not. Regarding the treatment response, other authors reported different results for the first insemination after treatments performed over cows with persistent corpus luteum (an average interval of 14.2 days) and an average interval of 63.72 days for pregnancy diagnosis at treated cows (Ruginosu et al., 2012).

The higher time interval from calving in artificial insemination in cows with persistent corpus luteum compared to cows from the control group, reveals that the problem of an extended postpartum interval is not just limited to pasturebased management systems, but is also recognized in more intensively managed dairy cows (Rhodes et al., 2003).

Concentrations of gonadotropins are very low in late pregnancy due to strong negative feedback from progesterone and estrogens. After calving, concentrations of FSH are increasing within 5 to 10 days in both milked and suckled cows, whereas circulating concentrations of LH generally start to increase between 10 to 20 days postpartum.

Pulsatile episodes of $\mathrm{LH}$ release are first detected around this time in milked cows, but are delayed in suckled cows, with pulses frequency of $\mathrm{LH}$ release being correlated with the interval to first ovulation (Lamming et al., 1981; Beam and Butler, 1997; Crowe et al., 1998).

A prolonged reproduction period in cows (as we observed in those from the control group, in contrast to cows with persistent corpus luteum), can be caused by several factors like: subclinical endometritis, a poor quality of recruited oocyte, subclinical or clinical mastitis, method used for artificial insemination, a properly detection of cows with oestrus signs.
Other factors that can lead to a prolonged reproduction period are: a bad semen management (semen packaging, conservation and semen thawing), quality of artificial insemination (moment of insemination, hygiene and the site of semen deposition) and various stressors, like environmental and management factors.

This possible hypothesis enunciated for cows with persistent corpus luteum can be also applied to those with ovarian cysts, which presented a lower average interval of reproduction period, compared to cows from the control group.

Our hypothesis, according to which the GnRH treatment of the cows with ovarian cysts is applicable, is also supported by other authors, according to which GnRH is the most effective for returning cows with an ovulatory cyst to a normal cyclic ovarian condition (Brito and Palmer, 2004). In response to treatment with GnRH, ovulation of the cyst does not occur, but other follicles present at the time of treatment may ovulate (Brito and Palmer, 2004).

Cows with ovarian cysts are capable of releasing LH in response to GnRH (Cantley et al., 1975). Thus, a single GnRH treatment has been the standard treatment for cows with ovarian cysts (Bierschwal et al., 1975; Seguin et al., 1976; Nakao et al., 1992; Osawa et al., 1995). However, a large proportion $(25 \%-39 \%)$ of cows with ovarian cysts treated with GnRH did not respond (Cantley et al., 1975; Nakao et al., 1992; Osawa et al., 1995; Tebble et al., 2001), probably because other follicles capable of responding to GnRH were not present (Tebble et al., 2001).

After the GnRH treatment and subsequent luteinization, the cyst becomes responsive to prostaglandin-F2 $\alpha \quad(\mathrm{PGF} 2 \alpha)$ because the steroidogenic synthesis pathway has switched from estradiol to progesterone.

The newly elevated levels of progesterone are responsible for a restoration of responsiveness to the positive feedback effect of estradiol, resulting in the resumption of normal cyclic ovarian activity after the release of endogenous PGF $2 \alpha$ and cyst regression (Brito and Palmer, 2004).

Directly correlated with reproduction period, a higher pregnancy index for cows from the control groups, may be caused either by lack of ovulation, or by a lack of synchronization between oestrus and ovulation, which explains the absence of fertilization in cows that, have shown oestrus 
signs. Similar results regarding pregnancy index from the experimental group have been reported by other authors (Ruginosu et al., 2012).

According to other authors, it's estimated that between $5-30 \%$ of known cows being at the moment of insemination, reveal increased progesterone concentrations (Senger et al., 1988), but this percentage can be variable depending on the flock size, thus, in larger farms, timing of the artificial insemination is not set properly. Increased progesterone levels lead to poor oestrus signs (Schopper D. et al., 1986) and reduce behavioral effects of estrogen.

Thus, a hormonal imbalance can be translated as modified behavioral signs, both qualitatively (an intensification of repeated breeding syndrome) and quantitative (prolonged oestrus signs) (Gustafsson et al., 1986).

Our results regarding the treatment response for cows with persistent corpus luteum, according to the season are supported by other researches; therefore, are clear seasonal patterns of oestrus detection, day to first service and conception rate in dairy cows (Cavestany D. et al., 1985; De Rensis et al., 2002 and Almier et al., 2002) and lower conception rates are consistently observed in summer months compared to winter months.

The effects of heat stress on fertility appear to carry into the autumn (Badinga et al., 1985; Roth et al., 1997 and Drew, 1999). The low fertility generally associated with the warm months of the year (June to September), remains in the autumn (October and November) even though the cows are no longer exposed to heat stress (Hansen PJ., 1997).

It has been suggested that this could be a lasting effect of heat stress during the hot months on the antral follicles that will develop into large dominant follicles 40-50 days later (Roth Z. et al., 2001).

The obtained results for the control group, support De Rensis's study (2003), in which he argues that heat stress during warm seasons is considered a major cause of low fertility worldwide, affecting mostly dairy cattle due to their high internal heat production related to high milk yield (De Rensis and Scaramuzzi, 2003; Wolfenson et al., 2000).

As for results that we obtained for cows treated against ovarian cysts according to the season, our research supports De Rensis's study
(2003), according to which, in heat stressed cows, the administration of GnRH induces follicular development and a healthy preovulatory follicle (Guzeloglu et al., 2001). In summer, the administration of $\mathrm{GnRH}$ to lactating dairy cows at oestrus increased the conception rate from 18 to 29\% (Ullah et al., 1996).

\section{CONCLUSION}

As a first conclusion, we can state that according to our results, obtained by administering the hormonal treatments, both in cows with persistent corpus luteum and in cows with ovarian cysts, we observed a visible decrease in reproduction period, from an average interval of 60 days for cows from the control group, to 51.6 days for cows with persistent corpus luteum and an average interval of 53.6 days for cows with ovarian cysts.

We also observed an improvement in conception rates for cows treated with hormonal medicine during warm season, thus this preliminary study supports the development of a more detailed research on several dairy cows farms in order to investigate the answer of different types of hormonal treatments against persistent corpus luteum and ovarian cysts.

\section{REFERENCES}

1. Almier M, De Rosa G, Grasso F, Napolitana F, Bordi A (2002). Effect of climate on the response of three oestrus synchronisation techniques in lactating dairy cows. Anim Reprod Sci 71:157-68.

2. Badinga L, Collier RJ, Thatcher WW, Wilcox CJ (1985). Effect of climatic and management factors on conception rate of dairy cattle in subtropical environment. J Dairy Sci 68:78-85.

3. Bierschwal CJ (1966). A clinical study of cystic conditions of the bovine ovary. J Am Vet Med Assoc 149:1591-1595.

4. Brito LFC, Palmer CW (2004). Cystic ovarian disease in cattle. Large Anim Vet Rounds 4:1-6.

5. Butler WR (2000). Nutritional interactions with reproductive performance in dairy cattle. Anim Reprod Sci 60-61:449-457.

6. Cantley TC, Garverick HA, Bierschwal CJ, Martin CE, Youngquist RS (1975). Hormonal responses of dairy cows with ovarian cysts to GnRH. J Anim Sci 41:1666-1673.

7. Cavestany D, El-Whishy AB, Foot RH (1985). Effect of season and high environmental temperature on fertility of Holstein cattle. J Dairy Sci 68:1471-8.

8. De Rensis F, Marconi P, Capelli T, Gatti F, Facciolongo F, Franzini $S$ et al (2002). Fertility in postpartum dairy cows in winter or summer following estrous synchronization and fixed time A.I. after the induction of an LH surge 
with Gonadotropin releasing hormone (GnRH) or human chorionic gonadotropin (hCG). Theriogenology 58:167587.

9. De Rensis F, Scaramuzzi RJ (2003). Heat stress and seasonal effects on reproduction in the dairy cow-a review. Theriogenology 60:1139-1151.

10. Drew B (1999). Practical nutrition and management of heifers and high yielding dairy cows for optimal fertility. Cattle Practice 7:243-8.

11. Grunert E (1981). Zur ovardystrophia beim Rind. Collegium Veterinarium :73-77.

12. Gustafsson H, Larsson K, Kindahl H, Madej A (1986). Sequential endocrine changes and behavior during oestrus and metoestrus in repeat breeder and virgin heifers. Anim Reprod Sci 10:261-273.

13. Guzeloglu A, Ambrose JD, Kassa T, Diaz T, Thatcher MJ, Thatcher WW (2001). Long term follicular dynamics and biochemical characteristics of dominant follicles in dairy cows subjected to acute heat stress. Anim Reprod Sci 66:15-34.

14. Hansen PJ (1997). Strategies for enhancing reproduction of lactating dairy cows exposed to heat stress. In: Proceedings of the 16th Annual Convention American Embryo Transfer Association, Madison, 62-72.

15. Moreira F, Orlandi C, Risco CA, Mattos R, Lopes F, Thatcher WW (2001). Effects of presynchronization and bovine somatotropin on pregnancy rates to a timed artificial insemination protocol in lactating dairy cows. J Dairy Sci 84:1646-1659.

16. Nakao T, Tomita M, Kanbayashi H, Takagi H, Abe T, Takeuchi Y, Ochiai H, Moriyoshi M, Kawata K (1992). Comparisons of several dosages of a $\mathrm{GnRH}$ analog with the standard dose of hCG in the treatment of follicular cysts in dairy cows. Theriogenology 38:137-145.

17. Opsomer G, Grohn YT, Hertl J, Coryn M, Deluyker H, de Kruif A (2000). Risk factors for post partum ovarian dysfunction in high producing dairy cows in Belgium: A field study. Theriogenology 53:841-857.

18. Opsomer G, Laevens H, Steegen N, de Kruif A (2000). A descriptive study of postpartum anoestrus in nine high- yielding dairy herds in Flanders. Vlaams Diergeneeskundig Tijdschrift 69:31-37.

19. Osawa T, Nakao T, Kimura M, Kaneko K, Takagi H, Moriyoshi M, Kawata K (1995). Fertirelin and buserelin compared by LH release, milk progesterone and subsequent reproductive performance in dairy cows treated for follicular cysts. Theriogenology 44:835-847.

20. Roth Z, Meidan R, Shaham-Albalancy A, Wolfenson D (1997). Immediate and delayed effects of heat stress on follicular development and function in lactating cows. In: Proceedings of the Annual Meeting American Society of Animal Science, Nashville, 367.

21. Roth Z, Meweidan R, Shaham-Albalancy A, Braw-Tal R, Wolfenson D (2001). Delayed effect of heat stress on steroid production in medium-size and preovulatory bovine follicles. Reproduction 121:745-51

22. Schopper D, Claus R (1986). Progesterone concentrations in milk fat around ovulation in the dairy cows; Differences between observed and silent heat. Zuchtlygiene 21:237240.

23. Seguin BE, Convey EM, Oxender WD (1976). Effect of gonadotropin-releasing hormone and human chorionic gonadotropin on cows with ovarian follicular cysts. Am J Vet Res 37:153-157.

24. Senger P L, Becker W C, Davidge S T, Hillers J K, Reeves J J (1988). Influence of corneal insemination on conception in dairy cattle. Journal of Animal Science 66:3010-3016.

25. Tebble JE, O'Donnell MJ, Dobson H (2001). Ultrasound diagnosis and treatment outcome of cystic ovaries in cattle. Vet Rec 148:411-3.

26. Ullah G, Fuquay JW, Keawhoong T, Clark BL, Pogue DE, Murphy EJ (1996). Effect of gonadotrophin-releasing hormone at estrus on subsequent luteal function and fertility in lactating Holstein during heat stress. J Dairy Sci 79:1950-3.

27. Wolfenson D, Roth Z, Meidan R (2000). Impaired reproduction in heat-stressed cattle: basic and applied aspects. Anim Reprod Sci 60-61:535-547.

28. http://orbi.ulg.ac.be/bitstream/2268/70544/1/R08_ Facteurs_generaux_2016.pdf 